\title{
PEMEROLEHAN SINTAKSIS ANAK USIA ENAM TAHUN ENAM BULAN (STUDI KUALITATIF PADA ZIYAN)
}

\author{
AULIA RAHMAH ZAMZAMI \\ UIN Syarif Hidayatullah Jakarta \\ rarazamzamil@gmail.com
}

Pertama Diterima: 5 Januari 2020

Bukti Akhir Diterima: 29 Juni 2020

\begin{abstract}
Abstrak
Seorang anak dalam berkomunikasi membutuhkan kemampuan yang didapatkan melalui proses pemerolehan bahasa. Proses pemerolehan setiap anak pun berbeda-beda, oleh karena itu penelitian ini penting untuk melihat sejauh mana seorang anak yang menjadi objek dalam penelitian ini mendapatkan pemerolehan bahasanya. Adapun tujuan dari penelitian ini ialah peneliti ingin melihat pemerolehan bahasa dalam bidang sintaksis terhadap anak usia 6 tahun 6 bulan yang bernama Sayyid Zikyan Milzam Harahap. Sumber data yang menjadi objek penelitian ini yaitu tuturan atau ucapan lisan anak usia 6 tahun 6 bulan yang bernama Sayyid Zikyan Milzam Harahap dalam bidang sintaksis. Metode yang dilakukan dalam penelitian ini yaitu dengan penelitian kualitatif melalui pendekatan deskriptif. Teknik pengumpulan data yang dilakukan peneliti dalam penelitian ini menggunakan teknik simak, cakap (wawancara), dan juga rekam. Hasil penelitian ini menunjukkan bahwa anak berusia 6 tahun 6 bulan bernama Ziyan sudah mampu menghasilkan kata maupun kalimat dalam setiap kegiatannya. Hal itu dapat dibuktikan dari tuturannya seharihari dengan lawan tuturnya yaitu peneliti, ibu kandung, dan juga saudara anak tersebut. Teori yang digunakan dalam menganalisis tuturan Ziyan yaitu merujuk pada Abdul Chaer tentang klasifikasi kalimat yang meliputi kalimat berita (deklaratif), kalimat tanya (interogatif), kalimat perintah (imperatif), dan kalimat seru (interjektif). Hasil dari penelitian ini yaitu Ziyan sudah mampu mengujarkan kalimat deklaratif sebanyak 10 kalimat, kalimat interogatif sebanyak 5 kalimat, kalimat imperatif sebanyak 2 kalimat, dan kalimat interjektif sebanyak 4 kalimat. Adapun simpulan yang dapat peneliti ambil melalui penelitian ini yaitu Ziyan sudah mampu menghasilkan bentuk-bentuk kalimat seperti yang tertera di hasil dan dapat disimpulkan bahwa Ziyan kurang mampu dalam menuturkan kalimat imperatif, hal itu dibuktikan dengan hasil tuturannya berbentuk kalimat interjektif yang tidak dominan.
\end{abstract}

Kata kunci: Pemerolehan Bahasa, Sintaksis, Anak Usia 6 tahun 6 bulan

\begin{abstract}
A child in communication needs abilities acquired through the process of language acquisition. The process of acquiring each child is different, so this research is important to see the extent to which the child gets the acquisition of his language. The purpose of this study is that researchers want to see the acquisition of language in the field of syntax for children aged 6 years 6 months named Sayyid Zikyan Milzam Harahap. The data source which is the object of this research is the speech or oral utterance of children aged 6 years 6 months named Sayyid Zikyan Milzam Harahap in the field of syntax. The method used in this research is qualitative research through a descriptive approach. Data collection techniques conducted by researchers in this study using the technique of listening, able (interview), and also record. The results of this study indicate that a child aged 6 years and 6 months named Ziyan has been able to produce words and sentences in each of his activities. This can be proven from his daily speech with his interlocutors namely researchers, biological mothers, and also the child's siblings. The theory used in analyzing Ziyan utterances is referring to Abdul Chaer about the classification of sentences which include news sentences (declarative), question sentences (interrogative), command sentences (imperative), and exciting sentences (interactive). The results of this study are that Ziyan has been able to pronounce declarative sentences of 10 sentences, interrogative sentences of 5 sentences, imperative sentences of 2 sentences, and interactive sentences of 4 sentences. The conclusions that researchers can take through this study are that Ziyan has been able to produce sentence forms as stated in the results
\end{abstract}


and it can be concluded that Ziyan is less able in speaking imperative sentences, this is evidenced by the results of speech in the form of non-dominant interactive sentences.

Keywords: Language Acquisition, Syntax, Children 6 years and 6 months

\section{PENDAHULUAN}

Bahasa merupakan alat komunikasi yang berfungsi untuk mengungkapkan gagasan, pengetahuan yang dimiliki, termasuk mengungkapkan hal-hal yang terlintas dalam benak seseorang. Kegiatan berbahasa tidak dapat dipisahkan dari kehidupan. Bahasa memegang peran penting karena tanpa bahasa, manusia tidak akan dapat melakukan interaksi terhadap manusia lainnya.

Secara tidak sadar, manusia sudah dikaruniai kemampuan berbahasa oleh Tuhan. Dikatakan seperti itu karena pada umumnya untuk kegiatan berbahasa itu sendiri, manusia sudah memiliki kemampuan berbahasa tanpa dibimbing oleh siapapun, karena kemampuan berbahasa itu murni didapatkan sejak lahir. Seorang anak akan tumbuh dan berkembang sesuai dengan perkembangan bahasanya. Perkembangan kemampuan komunikasi anak sejatinya sudah dimulai sejak ia lahir. Ketika anak baru lahir, ia akan mengeluarkan tangisannya sebagai bentuk komunikasi terhadap dunia dan orang yang berada di sekitarnya. Ketika beranjak balita, anak-anak mungkin akan mengeluarkan tangisannya sebagai bentuk usahanya dalam mendapatkan perhatian dari orang tua, dan sebagainya. Perkembangan kemampuan komunikasi anak tentunya tidak terlepas dari peran ibu dalam memegang kontrol terhadap dialog-dialog anak dalam berbahasa yang semakin berkembang seiring bertambahnya usia anak. Penggunaan bahasa sebagai alat komunikasi bagi anak terjadi melalui sebuah proses.

Proses pemerolehan bahasa serta perkembangannya pada anak adalah hal yang menarik untuk ditinjau dan diteliti dalam bidang psikolinguistik. Hal tersebut dapat kita lihat dari bagaimana proses pemerolehan bahasa yang tanpa sadar dilakukan oleh manusia, yang ternyata sangat rumit serta sukar untuk dibuktikan. Istilah pemerolehan menurut Dardjowidjojo (2010: 225) merupakan padanan yang terdapat dalam istilah Inggris yakniacquisition, yang berartisaat ia belajar bahasa ibunya, dalam proses penguasaan bahasa tersebut, anak melakukannya dengan cara yang natural atau alami. Pendapat lain dikuatkan oleh Simanjuntak (2009: 104), bahwa pemerolehan bahasa (language acquisition) adalah pemerolehan bahasa di sini merujuk pada proses anak saat memperoleh bahasa ibunya yang berlaku di pusat bahasa dalam otak.

Terdapat dari dua atau lebih ahli linguistik yang berpendapat, yang dapat mempelajari bahasa ialah makhluk hidup yaitu manusia, selain manusia tidak memiliki kemampuan itu karena hanya makhluk bernama manusia yang mendapatkan kemampuan berbahasa tersebut. Chomsky dalam hal ini mengemukakan gagasannya mengenai piranti yang dimiliki manusia, yakni LAD (Language Acquisition Device). Melalui LAD tersebut, manusia memiliki kapling kodrati yang terdapat dalam otak manusia sehingga ia dapat berbahasa, dan kemampuan berbahasa itu sudah melekat dalam otak manusia sejak ia lahir ke dunia, Chomsky dalam Dardjowijodjo (2010: 232). Sehingga, melalui LAD yang disebut piranti inilah pemerolehan bahasa pada anak menjadi mudah diperoleh. Skinner dalam Dardjowijodjo (2010: 235) juga mengemukakan mengenai pemerolehan bahasa, faktor lingkungan atau yang disebut sebagai nurture itulah yang lebih banyak mempengaruhi seorang anak dalam memperoleh bahasanya. Disebutkan bahwa bahasa juga disebut sebagai seperangkat 
kebiasaan yang diperoleh melalui latihan yang dilakukan anak secara terus-menerus. Beradasarkan beberapa pernyataan ahli tersebut dapat disimpulkan bahwa antara faktor alami dan faktor lingkungan saling bersinggungan dan tidak dapat dipisahkan.

Pemerolehan bahasa pertama juga dapat dikatakan sebagai bahasa pertama yang dikuasai oleh anak atau kita sebut sebagai B1 (bahasa ibu). Dalam rentang usia 6 sampai 10 tahun, anak pada umumnya sudah dapat menguasai tata bahasa baik itu bidang fonologi, bidang morfologi, bidang sintaksis, dan juga bidang semantik.

Tataran ilmu linguistik dalam pemerolehan dan perkembangan bahasa pada anak terdiri dari beberapa aspek, salah satu aspek yang khas terdapat pada anak yaitu aspek sintaksis. Pada periode awal anak mulai berbahasa dengan mengucapkan satu kata, setelah itu kalimat dua kata, setelah itu, kalimat tiga kata atau lebih, sampai seterusnya yaitu tahap kalimat lengkap dari segi strukturnya. 'Sintaksis' dalam istilahnya terlahir dari dua bidang bahasa, Belanda dan Inggris. Dalam bahasa Belanda, 'sintaksis' berasal dari kata syntaxis, sedangkan dalam bahasa Inggris berasal dari kata syntax. Pengertian 'sintaksis' sendiri yaitu bagian dari ilmu bahasa yang menganalisa dan mempelajari tidak hanya aturan dalam penyusunan kata, tetapi juga melingkupi aturan penyusunan frasa, klausa, bahkan kalimat yang bertujuan untuk membentuk suatu susunan yang memiliki sebuah pengertian (Maksan 1994: 58).

Maksan (1994: 48) menjabarkan tahap-tahap dari pemerolehan sintaksis pada anak terbagi menjadi beberapa bagian: (1) masa pra-lingual yang berlangsung ketika anak berusia 0-1 tahun. Pada masa tersebut, dikatakan bahwa anak masih berada dalam tahap pasif, di mana anak sudah mampu mendengar ujaran orang dewasa akan tetapi belum mampu untuk meniru dan mengujarkannya kembali, (2) masa kalimat satu kata (holofrasa) yang berlangsung ketika anak berusia 1-2 tahun. Di masa holofrasa tersebut anak sudah mampu mengujarkan apa yang terbesit dalam pikiran dan hatinya yang hanya diwakili anak tersebut melalui sebuah kata karena keterbatasan fisiknya, (3) masa kalimat dengan rangkaian kata singkat biasa disebut sebagai kalimat telegram ketika anak berusia 2-3 tahun. Sesuai dengan masanya, anak sudah mampu mengujarkan berupa kalimat singkat dalam beberapa kata, (4) masa konstruksi sederhana dan kompleks yang terjadi saat anak berusia 3-5 tahun, pada masa tersebut, anak sudah mampu menyusun rangkaian kalimat sederhana yang dikonstruksikan menjadi kalimat kompleks dalam setiap aktivitas dan kegiatannya.

Adapun Chaer (2009: 187) mengemukakan bahwa kalimat dapat diklasifikasikan dan dibedakan atas kalimat berita (deklaratif), kalimat tanya (interogatif), kalimat perintah (imperatif), dan kalimat seru (interjektif). Pertama, menurut Chaer (2009: 187) yang dimaksud dengan kalimat deklaratif yaitu kalimat yang mengandung informasi yang bertujuan agar orang lain dapat mengetahui informasi dari kalimat tersebut. Dalam menanggapi kalimat deklaratif ini, pembaca ataupun pendengar tidak dituntut untuk memberikan jawaban baik secara lisan maupun tulisan, pembaca atau pendengar cukup memberi komentar atau tanggapan terhadap kalimat deklaratif tersebut. Jika dilihat berdasarkan maksud penggunaan kalimatnya, kalimat deklaratif ini dapat dibedakan menjadi: a) bertujuan menyampaikan informasi terkait apa yang dialami oleh penutur, baik dari pengalaman maupun alam sekitar, b) bertujuan memberikan keputusan dari si penutur, selain keputusan, penutur dapat juga memberikan tanggapan atau penilaian, c) bertujuan 
menyampaikan perjanjian, nasihat, juga peringatan, d) bertujuan menyatakan ekspresi melalui ucapan selamat atau keprihatinan atas suatu musibah yang baru dialami, e) bertujuan merincikan penjelasan, atau keterangan terkait hal-hal yang membutuhkan perincian yang jelas kepada orang lain.Kedua, yang dimaksud dengan kalimat tanya (interogatif) adalah kalimat membutuhkan jawaban yang secara verbal, Chaer (2009: 189). Jawaban ini tidak hanya berupa pengakuan, namun juga mengandung keterangan, pendapat dan pikiran dari orang yang mendengar atau membacanya. Dilihat dari reaksi jawaban yang diberikan, kalimat tanya (interogatif) bertujuan untuk meminta pengakuan jawaban ya atau tidak, bertujuan meminta alasan atau keterangan terhadap sesuatu, bertujuan meminta tanggapan, komentar, atau penilaian.Ketiga, yang dimaksud dengan kalimat perintah (imperatif) adalah kalimat yang meminta pendengar maupun pembaca melakukan suatu tindakan, Chaer (2009: 197). Kalimat imperatif ini dapat berupa kalimat perintah dan kalimat larangan.Keempat, yang dimaksud dengan kalimat seru (interjektif) yaitu kalimat untuk menyatakan emosi, seperti karena kagum, kaget, terkejut, takjub, heran, marah, sedih, gemas, kecewa, tidak suka, dan sebagainya, Chaer (2009: 200). Kalimat interjektif yaitu kalimat yang bertujan untuk mengungkapkan emosi dalam bentuk yang bermacam-macam, terdapat sedih, marah, kecewa, gembira, bisa diawali dengan kata-kata wah,sungguh, alangkah, sangat, sekali, dan sebagainya.

Sebuah penelitian yang relevan yang berkaitan dengan pemerolehan bahasa di bidang sintaksis, seperti penelitian yang dilakukan oleh Impuni (2012) terkait "Pemerolehan Sintaksis Anak Usia Lima Tahun Melalui Penceritaan Kembali Dongeng Nusantara" telah menjelaskan bahwa pemerolehan kalimat tunggal dan kalimat majemuk sudah dapat dikatakan sesuai tahap perkembangan usia mereka, dimana penggunaan satu kata, dua kata, bahkan tiga kata masih sering dihasilkan secara sadar oleh anak-anak. Pemerolehan sintaksis dengan menceritakan kembali dongeng yang telah didengar dapat diterapkan sesuai dengan standar kompetensi yang ada. Selanjutnya, penelitian yang dilakukan oleh Putri Nasution (2009) dalam tesis yang berjudul "Kemampuan Berbahasa Anak Usia 3-4 Tahun (Prasekolah) di Play Group Tunas Mekar Medan: Tinjauan Psikolinguistik" telah memperoleh data bahwa para responden yaitu anak-anak yang berusia 3-4 tahun di Play Group Tunas Mekar Medan telah mampu berbahasa dengan baik dari pemerolehan fonologi, sintaksis, dan semantik. Jika pada tahap pemerolehan fonologi yang dialami anak tersebut mengalami pergantian bunyi-bunyi, baik yang disuarakan maupun tidak disuaraka, lain halnya dengan pemerolehan sintaksis dan semantik anak sudah mampu menggunakan kalimat gramatikal dan denotatif.

Penelitian ini dilakakukan pada seorang anak yang bernama Sayyid Zikyan Milzam Harahap (Ziyan). Ziyan, untuk selanjutnya disebut sebagai objek adalah anak pertama dari pasangan Henrizal Saidi Harahap dan Rabiatul Adawiyah, yaitu keluarga dari peneliti sendiri. Bahasa seharihari yang dipakai oleh kedua orang tua objek adalah bahasa Indonesia. Begitu pula dengan orangorang yang berada di lingkungannya. Adapun fokus penelitian ini adalah peneliti ingin meneliti ucapan lisan anak usia enam tahun enam bulan yang bernama Ziyan. Alasan peneliti memilih Ziyan sebagai objek penelitian adalah disebabkan peneliti merasa tertarik karena Ziyan sudah mampu mengucapkan kalimat-kalimat yang sudah mulai mengarah ke kalimat kompleks. 


\section{METODE PENELITIAN}

Penelitian ini dilakukan di Ciputat. Tempat tersebut merupakan rumah tempat tinggal Ziyan. Ziyan tinggal bersama kakaknya, ayah, dan ibu kandungnya. Peneliti sendiri merupakan tante dari Ziyan yang posisi rumahnya berdekatan dengan rumah Ziyan. Adapun objek penelitian dalam penelitian ini adalah seorang anak laki-laki bernama lengkap Sayyid Zikyan Milzam Harahap yang saat ini berusia enam tahun enam bulan. Kedua orang tua Ziyan menggunakan bahasa Indonesia dalam percakapan sehari-hari. Pemerolehan bahasa Ziyan sendiri dalam kehidupan sehari-hari menggunakan bahasa Indonesia. Pada penelitian ini peneliti memfokuskan pada pemerolehan bahasa Indonesianya.

Sugiyono (2013: 112) menjelaskan bahwa metode penelitian yaitu cara yang dilakukan peneliti dalam mendapatkan suatu data yang memiliki tujaun tertentu. Penelitian ini termasuk dalam penelitian kualitatif dengan menggunakan pendekatan deskriptif. Data yang dikumpulkan dalam penelitian deskriptif kualitatif adalah berupa kata-kata, gambar, dan bukan angka-angka Moleong (2013: 11). Penggunaan metode kualitatif dengan pendekatan deskriptif yang bertujuan untuk memberikan jabaran tentang pemerolehan sintaksis terkait kalimat bentuk deklaratif, interogatif, imperatif dan interjektif pada anak usia 6 tahun 6 bulan.

Untuk memperoleh data, teknik pengumpulan data yang dilakukan oleh peneliti adalah dengan teknik simak, cakap (wawancara), dan rekam. Sebagaimana yang dikemukakan oleh Sugiyono (2013: 224), teknik pengumpulan data tersebut merupakan langkah yang paling strategis dalam penelitian, karena tujuan utama dari penelitian ini adalah untuk mendapatkan data. Teknik simak yang dilakukan peneliti adalah dengan cara merekam setiap ujaran dari objek penelitian kemudian mentranskripsikan hasil simakan yang telah diperoleh. Selanjutnya, teknik cakap (wawancara) dilakukan oleh peneliti yang terlibat percakapan dengan Ziyan secara langsung.

Adapun langkah-langkah dalam menganalisis data tersebut adalah (a) mendeskripsikan data yang telah direkam dalam percakapan antara Ziyan dengan ibunya, saudaranya, maupun dengan peneliti sendiri, (b) menentukan jenis kalimat-kalimat yang diujarkan oleh Ziyan dengan mengklasifikasikan jenis kalimat yang berbentuk deklaratif, interogatif, imperatif, dan juga interjektif, (c) menginterpretasikan data yang telah didapatkan sesuai dengan permasalahan, dan (d) menarik kesimpulan dari hasil analisis data yang diperoleh.

\section{HASIL PENELITIAN DAN PEMBAHASAN}

\section{Hasil Penelitian}

\section{Transkripsi Data}

Di bawah ini adalah beberapa peristiwa tutur yang terjadi antara peneliti, Ziyan, Mama Ziyan, dan kakak (Balqis, kakak kandung Ziyan). Pada data 1, terjadi di sore hari ketika peneliti bertanya kepada Ziyan saat ia pergi bersama mamanya semalam. Ziyan sedang bermain gawai dan peneliti menghampirinya.

\section{Data 1}

Peneliti : Waktu Mama Dedek pergi itu hari apa? 
Ziyan : : Dedek lupa.

Peneliti : Hari Minggu bukan, Dek?

Ziyan : Oh iya, Dedek kan ikut, Tan. Ikut ke rumah yang di Sawangan.

Peneliti : Emang Dedek ikut?

Ziyan : Iya. Masa Tante gak liat Dedek sih?

Peneliti : Dedek pergi sama?

Ziyan : Pergi sama Mama. Tante sama Oma Umi kan?

Peneliti : Bukan.

Ziyan : Eh. Tante sama Tante Lily pulangnya kan? Sama Kak Balqis juga?

Peneliti : Iya.

Ziyan : Iya, Dedek ikut itu.

\section{Data 2}

Percakapan berikut terjadi ketika malam hari, setelah belajar Ziyan meminum susu yang telah dibuatkan oleh mamanya.

Peneliti : Dedek rencana libur tahun baru mau ke mana?

Ziyan : Nggak tau.

Peneliti : Waktu itu Mama Dedek bilang mau liburan ke mana?

Ziyan : Ke Dieng Tan, jauh banget itu.

Peneliti : Dedek kapan mulai libur sekolah?

Ziyan : Minggu depan.

Peneliti : Masuk sekolahnya kapan?

Ziyan : Masuk sekolah lama banget. Ngambil rapotnya minggu depan.

Peneliti : Dedek seneng gak kalau libur?

Ziyan : Seneng.

Peneliti : Kenapa?

Ziyan : Karena bisa pergi kemana aja. Bisa tidur bergadang juga Dedek.

Peneliti : Loh Dedek dikasih Mama kalau bergadang?

Ziyan : Kalau libur Dedek dibolehin bergadang, nonton TV, nonton You Tube sampe malam.

Peneliti : Emang kalau hari sekolah gak dibolehin ya?

Ziyan : Iya. Enakan libur ya Tante?

Peneliti : Hehehe. Yaudah, tidur gih, besok masuk sekolah pagi.

Ziyan : Nanti Dedek boboknya, belum ngantuk.

\section{Data 3}

Percakapan tersebut terjadi pada sore hari ketika Ziyan baru saja pulang dari sekolah dan peneliti memperlihatkan video membuat brownis kukus keju coklat.

Peneliti : Tadi Dedek inget gak bahan buat topingnya apa aja?

Ziyan : Inget. Ada coklat, choco cips sama keju. Udah jadi enak.

Peneliti : Jadi pengen beli deh Tante. Dedek mau beli gak?

Ziyan : Beli ngehabisin duit. Mending bikin aja Tan.

Peneliti : Iya juga. Hehehe. 


\section{Data 4}

Pada data (4) berikut ini, konteks tuturannya adalah ketika Balqis (kakak kandung Ziyan) menghampiri Ziyan yang sedang bermain di teras rumah. Antara Balqis dan Ziyan saling beradu minuman kesukaan yang sedang terkenal.

Balqis : Aku suka tau jelly-jelly gitu.

Ziyan : Iya, Dedek juga.

Balqis : Tapi Jelly Potter yang enak.

Ziyan : Ah, Jelly Potter gak enak.. Dedek sukanya Bubble.. Enak banget rasa coklat.

Balqis : Yaudah kan Ka Balqis sukanya yang jelly-jelly..

Ziyan : Dari pada jelly mendingan yang chat chat itu, apa ya namanya, Dedek lupa.

Balqis : Oh iya, yang waktu itu di rumah Tante Yeni, namanya Chatime.

Ziyan : Oh iya, Chatime juga enak banget. Bubblenya manis lagi.

\section{Data 5}

Pada data (5) berikut ini, konteks tuturan terjadi ketika di ruang tamu, ketika Ziyan dan Balqis sedang menonton TV. Ziyan ingin berada dalam satu sofa bersama kakaknya, namun kakaknya tidak mengizinkan karena satu alasan. Mama (Ibu kandung Ziyan dan Balqis) yang berusaha meleraikan pertengkaran antara mereka.

Ziyan : Ka Balqis geser sana! Dedek mau duduk juga!

Balqis : Ih gak bisa, ini itu udah gak muat lagi Dedek..

Ziyan : Yaudah Ka Balqis pindah aja, Dedek juga mau di sofa!

Balqis : Apaan sih Dedek, kan Ka Balqis yang duluan duduk.

Ziyan : (menangis) mamaa, liat deh Ka Balqisnya, Dedek nggak dikasih duduk di sofa...

Mama : Udah udah, Kakak ngalah ya, kasian Adeknya..

\section{Data 6}

Pada data (6) berikut, konteks tuturan terjadi ketika Ziyan ingin berangkat sekolah. Pada saat itu Ziyan merasa kesal karena ia merasa sepatu yang mau ia pakai ternyata sudah jelek, dan ingin memakai sepatu yang lain. Namun mama Ziyan yang berada dalam tuturan tersebut berusaha membujuk Ziyan agar mau memakai sepatu tersebut dan bisa berangkat ke sekolah secepatnya agar tidak terlambat.

Ziyan : Sepatu yang ini udah jelek..!

Mama : Siapa bilang jelek? Ini bagus buat Dedek, simple..

Ziyan : Nggak! Lebih bagus yang putih satu lagi loh ma,, ini mau copot talinya

Mama : Ini udah mama benerin tuh..

Ziyan : Nggak mau.. ini nggak enak banget dipake!

Mama : Ayo dipake aja Dedek, biar nggak telat sekolahnya..

Ziyan : Eehh.. yauda deh

\section{Data 7}

Pada data (7) berikut, konteks tuturan terjadi di sebuah restoran saat Ziyan dan kakaknya makan siang di restoran bersama ayah dan mamanya. 
Ziyan : Kak Balqis kalo makan es krim giginya ngilu nggak?

Balqis : Nggak, kalo Dedek?

Ziyan : Dedek juga nggak ngilu. Tapi kalo makan es batu gigi Dedek ngilu..

Balqis : Ya iyalah, Kak Balqis aja kalo disuruh makan es batu juga pasti ngilu Dek..

Tabel 1. Analisis struktur sintaksis ujaran Ziyan berdasarkan bentuk kalimat adalah sebagai berikut.

\begin{tabular}{|c|c|c|c|}
\hline No & Bentuk Sintaksis & Ujaran & Jumlah \\
\hline 1 & Kalimat Deklaratif & $\begin{array}{l}\text { 1. Dedek lupa. } \\
\text { 2. Ikut ke rumah yang di Sawangan. } \\
\text { 3. Pergi sama Mama. } \\
\text { 4. Nggak tau. } \\
\text { 5. Minggu depan. } \\
\text { 6. Karena (Dedek) bisa pergi kemana aja. (Dedek) bisa } \\
\text { tidur bergadang juga Dedek. } \\
\text { 7. Kalau libur Dedek dibolehin bergadang, nonton TV, } \\
\text { nonton You Tube sampe malam. } \\
\text { 8. Nanti Dedek boboknya, belum ngantuk. } \\
\text { 9. Ingat, ada coklat, choco cips sama keju. } \\
\text { 10. Enak banget rasa coklat. }\end{array}$ & 10 \\
\hline 2 & Kalimat Interogatif & $\begin{array}{l}\text { 1. Iya. Masa Tante gak liat Dedek sih? } \\
\text { 2. Tante sama Oma Umi kan? } \\
\text { 3. Iya. Enakan libur ya Tante? } \\
\text { 4. Dari pada jelly mendingan yang chat chat itu, apa ya } \\
\text { namanya, Dedek lupa. }\end{array}$ & 4 \\
\hline 3 & Kalimat Imperatif & $\begin{array}{l}\text { 1. Ka Balqis geser sana! Dedek mau duduk juga! } \\
\text { 2. Yaudah Ka Balqis pindah aja, Dedek juga mau di sofa! }\end{array}$ & 2 \\
\hline 4 & Kalimat Interjektif & $\begin{array}{l}\text { 1. Ke Dieng Tan, jauh banget itu. } \\
\text { 2. Masuk sekolah lama banget. } \\
\text { 3. Oh iya, Chatime juga enak banget. Bubblenya manis } \\
\text { 4agi. } \\
\text { 4. Sepatu yang ini udah jelek..! }\end{array}$ & 4 \\
\hline & Total & & 20 \\
\hline
\end{tabular}

\section{Pembahasan}

\section{Pola Kalimat Deklaratif Anak Usia Enam Tahun Enam Bulan}

Definisi dari kalimat deklaratif yaitu kalimat berita yang bertujuan untuk menyampaikan pernyataan yang ditujukan kepada orang lain. Kalimat dalam modus deklaratif ini tidak memerlukan jawaban baik secara lisan maupun non lisan (tindakan). Akan tetapi, diberikan tanggapan atau komentar dari pendengar atau pembaca bila dianggap perlu. Contoh pola kalimat deklaratif anak usia enam tahun enam bulan dapat dilihat dalam tuturan berikut.

\section{Dedek lupa.}

Jenis kalimat tersebut adalah jenis kalimat yang berpola subjek - predikat (S - P). Unsur pengisi subjeknya (S) berupa nomina yaitu Dedek (nama panggil Ziyan di rumah), sedangkan unsur pengisi predikatnya (P) yaitu lupa. Adapun konteks dari pernyataan tersebut yaitu ketika ditanya pada waktu itu pergi ke mana, Ziyan ingin memberitahu bahwa ia lupa pergi ke mana. 


\section{Ikut ke rumah yang di Sawangan.}

Jenis kalimat tersebut adalah jenis kalimat yang berpola predikat - keterangan tempat ( $\mathrm{P}$ Ket). Unsur pengisi predikatnya (P) berupa verba yaitu kata ikut, sedangkan unsur pengisi keterangan tempat (Ket) berupa nomina yaitu rumah di Sawangan. Adapun konteks dari pernyataan tersebut yaitu Ziyan ingin memberitahu kepada peneliti bahwa waktu itu ia ikut pergi ke rumah yang berada di Sawangan.

\section{Pergi sama Mama.}

'Pergi dengan Mama'.

Jenis kalimat tersebut adalah jenis kalimat yang berpola predikat - pelengkap $(\mathrm{P}-\mathrm{Pel})$. Unsur pengisi predikatnya $(\mathrm{P})$ berupa verba yaitu pada kata pergi. Sedangkan unsur pengisi pelengkapnya (Pel) yaitu pada frasa dengan mama. Konteks dari tuturan tersebut yaitu Ziyan ingin memberi tahu kepada peneliti ketika pergi ke Sawangan, ia pergi bersama ibunya.

\section{Nggak tau.}

'Tidak tahu'.

Jenis kalimat tersebut berpola predikat $(\mathrm{P})$ saja. Unsur pengisi predikatnya $(\mathrm{P})$ berupa verba yaitu terdapat pada kata tidak tahu. Konteks tuturan tersebut terjadi pada saat peneliti bertanya kepada Ziyan ingin liburan kemana pada saat tahun baru, namun Ziyan memberitahu kepada peneliti bahwa ia tidak tahu jika liburan tiba akan pergi ke mana.

\section{Minggu depan.}

Jenis kalimat tersebut berpola keterangan dengan kata lain keterangan waktu (Ket). Unsur pengisinya yaitu keterangan waktu yang ditunjukkan dengan frasa minggu depan. Konteks tuturan tersebut yaitu ketika peneliti bertanya kapan Ziyan akan mengambil raport, dan Ziyan memberitahu kepada peneliti bahwa ia akan menerima raport minggu depan.

\section{Karena (Dedek) bisa pergi kemana aja. (Dedek) bisa tidur bergadang juga Dedek.}

Jenis kalimat untuk klausa pertama adalah jenis kalimat yang berpola subjek - predikat pelengkap ( $\mathrm{S}-\mathrm{P}-\mathrm{Pel}$ ). Unsur pengisi subjeknya (S) berupa nomina yang terdapat pada kata Dedek, di mana subjek mengalami pelesapan, unsur pengisi predikat (P) berupa verba yang terdapat pada kata bisa pergi, dan unsur pengisi pelengkapnya (Pel) yaitu kemana aja 'kemana saja'. Jenis kalimat untuk klausa kedua adalah jenis kalimat yang berpola subjek - predikat ( $\mathrm{S}-\mathrm{P})$. Unsur pengisi subjeknya (S) berupa nomina yaitu Dedek, di mana dalam tuturan tersebut subjek Dedek mengalami pelesapan, sedangkan unsur pengisi predikatnya $(\mathrm{P})$ berupa verba yaitu tidur bergadang. Konteks tuturan tersebut yaitu ketika Ziyan memberi tahu bahwa ia lebih suka libur. Karena di masa 
liburlah Ziyan bisa merasakan pergi ke mana saja, dan juga diizinkan untuk tidur larut malam oleh orangtuanya.

Kalau libur Dedek dibolehin bergadang, nonton TV, nonton You Tube sampe malam.

Jenis kalimat tersebut adalah jenis kalimat yang berpola keterangan - subjek - predikat 1 predikat 2 - pelengkap (Ket $-\mathrm{S}-\mathrm{P} 1-\mathrm{P} 2-\mathrm{Pel}$ ). Unsur pengisi keterangan waktunya (Ket) yaitu kalau libur, unsur pengisi subjeknya (S) berupa nomina terdapat pada kata Dedek, unsur pengisi predikatnya (P1) berupa verba yaitu dibolehin, unsur pengisi predikat (P2) berupa verba yaitu bergadang, nonton TV, nonton You Tube, sedangkan unsur pengisi pelengkapnya (Pel) berupa keterangan waktu yaitu sampai malam. Konteks tuturan tersebut terjadi ketika peneliti bertanya apa yang membuat Ziyan senang ketika libur, dari tuturan tersebut Ziyan ingin memberitahu bahwa keuntungan-keuntungan yang ia dapatkan saat libur yaitu bisa tidur bergadang, diizinkan untuk menonton TV dan You Tube hingga larut malam.

\section{Nanti Dedek boboknya, belum ngantuk.}

'Nanti Dedek tidurnya, belum ngantuk.'

Jenis kalimat tersebut yaitu jenis kalimat berpola (Ket $-\mathrm{S}-\mathrm{P}$ ) untuk kalimat pertama, dan berpola predikat (P) untuk kalimat kedua. Pada kalimat atau klausa pertama, unsur pengisi keterangan (Ket) mengacu kepada keterangan waktu yaitu nanti, unsur pengisi subjeknya (S) berupa nomina terdapat pada kata Dedek, dan unsur pengisi predikatnya (P) berupa verba terdapat pada kata tidur. Pada kalimat kedua, unsur pengisi predikatnya (P) berupa verba terdapat pada kata ngantuk. Konteks tuturan terjadi pada saat malam hari, ketika habis belajar, peneliti menyuruh Ziyan untuk segera tidur agar esok hari tidak terlambat ke sekolah, tetapi Ziyan malah memberi tahu kepada peneliti bahwa ia belum ngantuk.

Ingat, ada coklat, choco cips sama keju.

Jenis kalimat tersebut yaitu jenis kalimat berpola $(\mathrm{P}-\mathrm{Pel})$. Unsur pengisi predikatnya $(\mathrm{P})$ berupa verba terdapat pada kata ingat, sedangkan unsur pengisi pelengkapnya (Pel) terdapat pada coklat, chocochips, dan keju. Konteks tuturan tersebut yaitu Ziyan berusaha memberitahu bahwa bahan-bahan topping untuk melengkapi brownies terdiri dari coklat, choco cips, dan keju.

\section{Enak banget rasa coklat.}

Jenis kalimat tersebut yaitu jenis kalimat berpola predikat - subjek $(\mathrm{P}-\mathrm{S})$. Unsur pengisi predikatnya $(\mathrm{P})$ berupa adjektiva yaitu enak banget, sedangkan unsur pengisi subjeknya (S) terdapat pada rasa coklat. Adapun konteks pada tuturan tersebut menerangkan bahwa Ziyan ingin memberitahu bahwa rasa coklat itu sangat enak. 
Berdasarkan data yang diperoleh tersebut, dapat disimpulkan bahwa Ziyan yang berusia enam tahun enam bulan dapat menuturkan kalimat-kalimat deklaratif dengam pola $(\mathrm{S}-\mathrm{P}),(\mathrm{P}-\mathrm{Ket}),(\mathrm{P}-$ Pel), (P), (Ket), (S - P - Pel), (P - S ), (Ket - S - P - Pel), dan pola (Ket - S - P). Pola yang paling dominan dalam tuturan deklaratif Ziyan yaitu pola $(\mathrm{S}-\mathrm{P})$.

\section{Pola Kalimat Interogatif Anak Usia Enam Tahun Enam Bulan}

Yang dimaksud dengan kalimat tanya (interogatif) adalahkalimat yang mengharapkan adanya jawaban secara verbal (Chaer, 2009: 189). Jawaban ini tidak hanya berupa pengakuan, namun juga mengandung keterangan, pendapat dan pikiran dari orang yang mendengar atau membacanya. Dilihat dari reaksi jawaban yang diberikan, kalimat tanya (interogatif) dibedakan adanya: (a) kalimat interogatif yang meminta unsur jawaban ya atau tidak, (b) kalimat interogatif yang meminta keterangan dari orang yang mendengar atau membaca dalam kalimat, (c) kalimat interogatif yang bertujuan meminta alasan, (d) kalimat interogatif yang bertujuan meminta pendapat orang lain, (e) kalimat interogatif yang menyungguhkan, biasanya menggunakan kata depan apa, siapa, di mana, mengapa, bagaimana, dan sebagainya. Berikut ini terdapat beberapa tuturan Ziyan yang termasuk ke dalam kalimat interogatif yaitu:

\section{Iya. Masa Tante gak liat Dedek sih?}

Kalimat tersebut termasuk jenis kalimat interogatif yang berpola meminta jawaban "ya" atau "tidak", atau kalimat yang berusaha menyungguhkan. Konteks dalam tuturan tersebut yaitu Ziyan ingin bertanya kepada peneliti untuk meyakinkan apakah benar peneliti tidak melihat dia pada saat di lokasi kejadian.

\section{Tante sama Oma Umi kan?}

Kalimat tersebut termasuk jenis kalimat interogatif yang berpola meminta jawaban berupa pengakuan ya atau tidak, atau kalimat yang berusaha menyungguhkan. Konteks dalam tuturan tersebut yaitu Ziyan ingin bertanya kepada peneliti untuk meyakinkan apakah benar peneliti pergi bersama Oma Umi pada saat ingin pergi ke Sawangan.

\section{Iya. Enakan libur ya Tante?}

Kalimat tersebut termasuk jenis kalimat interogatif yang berpola meminta jawaban berupa ya atau tidak. Konteks tuturan tersebut yaitu Ziyan ingin mendengar jawaban ya atau tidaknya peneliti mengenai perasaan yang dialami ketika libur.

Dari pada jelly mendingan yang chat chat itu, apa ya namanya, Dedek lupa.

Kalimat tersebut termasuk jenis kalimat interogatif yang berpola ingin meminta pendapat atau buah pikiran dari orang lain, dengan menggunakan kata tanya apa. Seperti dalam konteks tuturan 
tersebut yaitu Ziyan mencoba mengingat-ingat nama minuman yang pernah diminum olehnya, namun karena lupa ia pun menanyakan hal tersebut agar mendapat keterangan mengenai minuman yang pernah diminum olehnya.

\section{Kak Balqis kalo makan es krim giginya ngilu nggak?}

Kalimat tersebut termasuk jenis kalimat interogatif yang berpola meminta jawaban "ya" atau "tidak". Konteks tuturan tersebut yaitu Ziyan ingin mendengar jawaban ya atau tidak dari kakak kandungnya apakah kakak merasakan hal yang sama ketika memakan eskrim seperti ngilu yang dirasakan oleh Ziyan sendiri.

Berdasarkan data yang diperoleh tersebut, dapat disimpulkan bahwa pola kalimat interogatif yang dituturkan oleh Ziyan yang berusia enam tahun enam bulan menggunakan pola-pola kalimat interogatif yang meminta jawaban "ya" atau "tidak", serta meminta keterangan atau pendapat orang lain dalam memecahkan masalah pertanyaan.

\section{Pola Kalimat Imperatif Anak Usia Enam Tahun Enam Bulan}

Kalimat imperatif yang dimaksud yaitu kalimat perintah yang meminta orang yang mendengar atau membaca melakukan suatu tindakan. Kalimat imperatif ini dapat berupa kalimat perintah dan kalimat larangan. Adapun beberapa tuturan yang termasuk dalam kalimat imperatif dalam tuturan Ziyan yaitu:

\section{Ka Balqis geser sana! Dedek mau duduk juga!}

Kalimat tersebut termasuk dalam kalimat imperatif yang berpola memerintah. Konteks dalam tuturan tersebut yaitu terjadi di ruang tamu. Ziyan yang merasa kesal karena tidak mendapat ruang untuk duduk, akhirnya memerintahkan kepada kakaknya bahwa ia harus berpindah tempat saat itu juga.

\section{Yaudah Ka Balqis pindah aja, Dedek juga mau di sofa!}

Kalimat tersebut termasuk dalam kalimat imperatif yang berpola memerintah. Konteks dalam tuturan tersebut yaitu terjadi di ruang tamu. Ziyan yang merasa kesal karena kakaknya tidak juga mendengar perintahnya, ia pun berusaha mempertegas lagi bahwa kakaknya harus berpindah tempat, karena Ziyan ingin bisa duduk di sofa.

Berdasarkan data yang diperoleh tersebut, kalimat imperatif yang dominan dituturkan oleh anak berusia enam tahun enam bulan bernama Ziyan yaitu kalimat imperatif berpola memerintah. Dapat disimpulkan juga bahwa di dalam tuturan Ziyan, tidak terdapat kalimat imperatif yang berpola melarang. 


\section{Pola Kalimat Interjektif Anak Usia Enam Tahun Enam Bulan}

Yang dimaksud dengan kalimat interjektif yaitukalimat untuk menyatakan emosi, seperti karena kagum, kaget, terkejut, takjub, heran, marah, sedih, gemas, kecewa, tidak suka, dan sebagainya (Chaer, 2009: 200). Kalimat interjektif yaitu kalimat yang bertujan untuk mengungkapkan emosi dalam bentuk yang bermacam-macam, terdapat sedih, marah, kecewa, gembira, bisa diawali dengan kata-kata wah,sungguh, alangkah, sangat, sekali, dan sebagainya. Beberapa tuturan yang termasuk ke dalam kalimat interjektif dapat dilihat sebagai berikut.

\section{Ke Dieng Tan, jauh banget itu.}

Kalimat tersebut termasuk ke dalam jenis kalimat interjektif berpola menunjukkan kekagumannya terhadap jarak suatu tempat. Konteks di dalam tuturan tersebut yaitu Ziyan berusaha menunjukkan kekagumannya terhadap tempat yang akan menjadi objek liburannya di tahun baru ternyata sangat jauh dari apa yang dibayangkan.

\section{Masuk sekolah lama banget.}

Kalimat tersebut termasuk ke dalam jenis kalimat interjektif berpola menunjukkan ekspresi kecewa Ziyan. Konteks di dalam tuturan tersebut menerangkan bahwa Ziyan yang sebentar lagi akan liburan sekolah, ketika ditanya mengenai kapan ia akan masuk sekolah, ia pun menjawab pertanyaan tersebut dengan nada kekecewaan. Hal tersebut menunjukkan bahwa Ziyan tidak suka jika ia mendapat jatah liburan yang lama.

\section{Oh iya, Chatime juga enak banget. Bubblenya manis lagi.}

Kalimat tersebut termasuk ke dalam jenis kalimat interjektif berpola menunjukkan ekspresi kekagumannya atau memuji sesuatu. Konteks dalam tuturan tersebut yaitu Ziyan ingin menunjukkan ekspresi kesukaannya terhadap minuman yang disukainya dengan cara memuji rasa yang ada pada minuman tersebut.

\section{Sepatu yang ini udah jelek..!}

Kalimat tersebut termasuk ke dalam jenis kalimat interjektif berpola marah dengan alasan suatu hal. Konteks di dalam tuturan tersebut menerangkan bahwa Ziyan yang pada saat itu ingin berangkat ke sekolah, mendapati sepatu yang ia rasa sudah jelek. Ziyan menunjukkan ekspresi kekesalan atau kemarahannya karena sepatu yang akan ia pakai itu ternyata sudah jelek dan menurutnya tidak nyaman untuk digunakan ke sekolah.

Berdasarkan data yang diperoleh tersebut dapat disimpulkan bahwa pola-pola kalimat imperatif yang dituturkan Ziyan terdiri dari beberapa pola, yaitu kekaguman, kekecewaan, memuji, dan di sisi lain kemarahan. Pola yang dominan ditunjukkan Ziyan di dalam tuturannya lebih banyak 
menunjukkan pola ekspresi negatif yaitu kekecewaan, kemarahan, sedangkan pola yang tidak dominan yaitu kalimat interjektif berpola menunjukkan eskpresi memuji terhadap sesuatu.

\section{PENUTUP}

Berdasarkan analisis data dan pembahasan hasil penelitian terhadap Ziyan yang berusia enam tahun enam bulan seperti yang telah diperoleh tersebut adalah sebagai berikut. Ziyan yang berusia enam tahun enam bulan sudah dapat menuturkan kalimat-kalimat deklaratif dengam pola $(\mathrm{S}-\mathrm{P}),(\mathrm{P}$ - Ket), (P - Pel), (P), (Ket), (S - P - Pel), (P - S), (Ket - S - P - Pel), dan pola (Ket - S - P). Pola yang paling dominan dalam tuturan deklaratif Ziyan yaitu pola $(\mathrm{S}-\mathrm{P})$.

Dalam menuturkan kalimat interogatif, Ziyan yang berusia enam tahun enam bulan sudah mampu menggunakan pola-pola kalimat interogatif yang meminta jawaban "ya" atau "tidak", serta meminta keterangan atau pendapat orang lain dalam memecahkan masalah pertanyaan. Dalam menurutkan kalimat imperatif, Ziyan sudah mampu menuturkan kalimat imperatif berpola memerintah. Dapat disimpulkan juga bahwa di dalam tuturan Ziyan, tidak terdapat kalimat imperatif yang berpola melarang. Terakhir, dalam menuturkan kalimat interjektif, Ziyan sudah mampu menuturkan dengan menggunakan pola-pola kalimat imperatif yang terdiri dari beberapa pola, yaitu kekaguman, kekecewaan, memuji, dan di sisi lain kemarahan. Pola yang dominan ditunjukkan Ziyan di dalam tuturannya lebih banyak menunjukkan pola ekspresi negatif yaitu kekecewaan, kemarahan, sedangkan pola yang tidak dominan yaitu kalimat interjektif berpola menunjukkan eskpresi memuji terhadap sesuatu. 


\section{DAFTAR PUSTAKA}

Chaer, Abdul. 2009. Psikolinguistik: Kajian Teoritik. Cetakan Kedua. Jakarta: PT Rineka Cipta.

Djardjowidjojo, Soenjono. 2010. Psikolinguistik Pengantar Pemahaman Bahasa Manusia. Jakarta: Yayasan Obor Indonesia.

Impuni. 2012. Pemerolehan Sintaksis Anak Usia Lima Tahun Melalui Penceritaan Kembali Dongeng Nusantara. Jurnal Penelitian Humaniora, Vol. 13, No. 1, 30 Februari2012.

Maksan, Marjusman. 1994. Psikolinguistik. Padang: IKIP Padang Press.

Moleong, Lexy J. 2013. Metode Penelitian Kualitatif. Edisi Revisi. Bandung: PT. Remaja Rosdakarya.

Simanjuntak, Mangantar. 2009. Pengantar Neuropsikolinguistik, Menelusuri Bahasa, Pemerolehan Bahasa dan Hubungan Bahasa dengan Otak. Perpustakaan Nasional Republik Indonesia.

Sugiyomo. 2013. Metode Penelitian Kuantitatif Kualitatif, dan R \& D. Bandung: Alfabeta. 